\title{
Colonic delivery of film coated meloxicam tablets using natural polysaccharide polymer mixture
}

\author{
*Ganesh Godge ${ }^{1}$, Shivanand Hiremath ${ }^{2}$ \\ ${ }^{1}$ Padmashri Dr. Vitthalrao Vikhe Patil Foundation's College of Pharmacy, Vilad Ghat, Ahmednagar-414111, Maharashtra, India \\ ${ }^{2}$ PRES'S College of Pharmacy, Sinnar, Nashik-422101, Maharashtra, India
}

\begin{abstract}
Now days natural polysaccharides are extensively used for the development of solid dosage forms for delivery of drug to the colon. The objective of the present study was to develop a site-specific drug, single unit formulation allowing targeted drug release in the colon. Solid unit dosage forms were prepared using polysaccharides or synthetic polymer included xanthan gum, pectin, chitosan and Eudragit-E. Meloxicam was used as a model drug. The prepared tablets were enteric coated with Eudragit-S 100 to give protection in the stomach. The coated tablets were tested in-vitro for their suitability as colon specific drug delivery systems. The dissolution data so obtained illustrates that enteric coated tablets containing $3 \%$ chitosan as a binder, showed only $12.5 \%$ drug release in the first $5 \mathrm{~h}$, which is the usual upper gastrointestinal transit time, whereas, tablets prepared using xanthan gum as binder, were unable to protect drug release under similar conditions. Solid formulations containing pectin as a binder formed timedependent release formulations. $28 \%$ drug release was observed in the usual upper gastrointestinal tract conditions, when used in a concentration of $5.92 \%$ in the tablets.
\end{abstract}

Key Words: Solid dosage forms, synthetic polymer, time dependent release, chitosan, xanthan gum, Eudragit-E.

\section{INTRODUCTION}

Colon which is known as distal part of GIT was until recently, considered as a site for water reabsorption and residual carbohydrate fermentation. However, it is currently being viewed as a site for drug delivery. Presently, Colonic drug delivery is not only restricted to treatment of local disorders but also for systemic drug delivery. This distal part of GIT now has emerged completely for being considered as a site for administration of protein and peptide drug (Reddy et al., 1999). This is because colon provides a less hostile environment for drugs due to low diversity and intensity of digestive enzymatic activities, and a near neutral $\mathrm{pH}$. Moreover colonic drug delivery is likely to increase; due to colon transit time may last for upto $78 \mathrm{~h}$, the time available for drug absorption. Suita-

\footnotetext{
*Corresponding Author:

Godge Ganesh Raosaheb, Assistant Professor

Padmashri Dr. Vitthalrao Vikhe Patil Foundation's College of Pharmacy

Vilad Ghat, Ahmednagar-414111

Maharashtra, India.

E-mail: grgodge@yahoo.com

Contact No.: +919028757508
}

bility of colonic drug delivery as a site for drug administration appears promising because this site is more responsive to absorption enhancers. Moreover, when a delay in drug absorption is required from a therapeutic point of view e.g. in case of diurnal asthma, angina, arthritis, etc. colonic delivery of drugs may be extremely useful (Kinget $e t$ al., 1998).

In the recent studies, colon targeted drug delivery systems are gaining importance to treat local pathologies of the colon (crohn's disease, inflammatory bowel disease, colonic cancer) and also for the systemic delivery of protein and peptide drugs. This is because the peptide and protein drugs gets destroyed or inactivated in acidic environment of the stomach or by pancreatic enzymes in the small intestine (Ojha et al., 2012).

It is widely acknowledged that the extent of gastrointestinal tract drug absorption is related to contact time with the small intestinal mucosa. Thus, small intestinal transit time is an important parameter for drugs that are incompletely absorbed. Basic 
human physiology with the details of gastric emptying, motility patterns, and physiological and formulation variables affecting the cosmic emptying are summarized (Chandel et al., 2012).

Different systems are being developed for colonspecific drug delivery. These include covalent linkage of a drug with a carrier, coating with $\mathrm{pH}$ sensitive polymers, time dependent release systems, and enzymatically controlled delivery systems (Leopold et al., 1999). Enteric coated systems are the most commonly employed for colonic drug delivery, but the disadvantage of this system is that the $\mathrm{pH}$ difference between small intestine and colon is not being very pronounced. These delivery systems do not allow reproducible drug release. Timecontrolled release system may be, swellable, soluble coating, or a matrix type, which can resist the release of majority of drug from the formulation for an additional $3 \mathrm{~h}$ (i.e. the usual small intestinal transit time) and can deliver drug primarily to the colon (Chourasia and Jain, 2003; Yang et al., 2002; Sinha and Kumria, 2001; Sinha and Kumria, 2003; Liu et al., 2003).

Various polysaccharides/polymers are used conventionally in the tablet formulations to retard to retard drug release. These have been used either as matrices or as a coating material. A high concentration of polymer is required generally for matrices. Moreover, these can be used as binders in tablets. These polysaccharides/polymers in the form of solution can be used as binders probably on drying enables the granules to be coated by them (Yen et al., 1964; Bankar et al., 1992).

Thus, varying the polysaccharide/polymer and their concentration affects drug release from the prepared tablet. Based on the above assumption, three different polysaccharides viz. xanthan gum, pectin, chitosan and a pH sensitive polymer, Eudragit-L100 were selected for the present study.

The objective of the present study was to formulate a dosage form which was enteric coated to prevent drug release in the stomach and had an additional lag phase in the formulation to retard drug release in the small intestine. Various attempts were already been occurred in past to design enteric coated systems with such lag phases; their large scale manufacturing requires a lot of skills and technological advancement (MacNeil et al., 1990 and Niwa et al., 1995) Therefore, an attempt was made to formulate a dosage form, using the usual tableting techniques which could be formulated easily, and usual tableting ingredients, with some modification in the method of processing of the ingredients.

\section{MATERIALS AND METHODS}

Meloxicam was a generous gift from Modern laboretories Limited (Indore) India. Xanthan gum, pectin, chitosan (degree of deacetylation $>85 \%$ ), Eudragit-S 100 and Eudragit-E were obtained as gift samples from Evonik industries. All other ingredients used in the preparation and coating of tablets were of Analytical Pharmacopoeial.

\section{Preparation of binder solutions}

Binder solutions of the polysaccharides were prepared by solubilizing the weighed amount of polysaccharide (as per Table 1) with distilled water. This mixture was allowed to stand with intermittent mixing for $0.5 \mathrm{~h}$, so as to enable the polysaccharides to swell. The paste thus formed was then used as a binder for the powder mix during wet granulation. In case of chitosan a $1 \% \mathrm{v} / \mathrm{v}$ solution of acetic acid in distilled water was used. The quantities of polysaccharide/polymer used were as mentioned in Table $\mathbf{1}$.

\section{Preparation of granules}

All the powdered ingredients were weighed, mixed and granulated with the binder solution/paste prepared as above. This mixture was thoroughly blended manually and passed through a sieve no.80.

Table 1: Quantity of binder in $\mathrm{g}$ for 75 tablets.

\begin{tabular}{lllllll}
\hline $\begin{array}{l}\text { Sl. } \\
\text { No. }\end{array}$ & $\begin{array}{l}\text { Formula- } \\
\text { tion code }\end{array}$ & $\begin{array}{l}\text { Xanthan } \\
\text { gum }\end{array}$ & Pectin & \multicolumn{2}{c}{ Chitosan Eudragit E } & $\begin{array}{l}\text { \% of } \\
\text { binder }\end{array}$ \\
\hline 1 & XG3 & 0.300 & -- & -- & -- & 1.77 \\
2 & XG6 & 0.600 & -- & -- & -- & 3.55 \\
3 & XG9 & 0.900 & -- & -- & -- & 5.32 \\
4 & PT2 & -- & 0.200 & -- & -- & 1.18 \\
5 & PT3 & -- & 0.300 & -- & -- & 1.77 \\
6 & PT4 & -- & 0.400 & -- & -- & 2.37 \\
7 & CH2 & -- & -- & 0.200 & -- & 1.18 \\
8 & CH3 & -- & -- & 0.300 & -- & 1.77 \\
9 & CH4 & -- & -- & 0.400 & -- & 2.37 \\
10 & EE3 & -- & -- & -- & 0.300 & 1.77 \\
11 & EE6 & -- & -- & -- & 0.600 & 3.55 \\
12 & EE9 & -- & -- & -- & 0.900 & 5.32 \\
13 & EE12 & -- & -- & -- & 1.2 & 7.10 \\
\hline
\end{tabular}




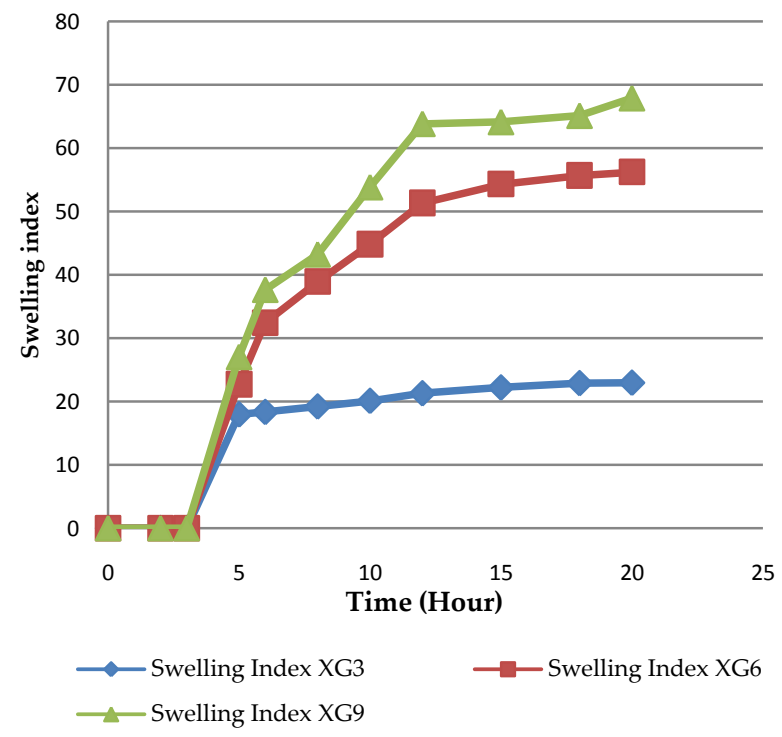

Figure 1: Swelling index vs. time graph of $X G$ tablets at $6.8 \mathrm{pH}\left(37^{\circ} \mathrm{C}\right)$.

The granules prepared were dried in a hot air oven at a temperature between 30 and $40^{\circ} \mathrm{C}$ for $4 \mathrm{~h}$. The dried granules were screened, mixed with lubricants and stored in a desiccators for tableting.

\section{Preparation of tablets}

Tablets weighing $135 \mathrm{mg}$ containing $15 \mathrm{mg}$ of meloxicam were individually punched on a rotary punch tableting machine (CAP Works, Ahmedabad, India) using concave die-punch. The tablets had hardness between 5 and $7 \mathrm{~kg} / \mathrm{cm}^{2}$. Various in process quality control tests were performed on the prepared tablets viz., content uniformity, hardness, friability, disintegration, etc.

\section{Coating of tablets}

All prepared batches of the tablet were coated with a $12.5 \% \mathrm{w} / \mathrm{v}$ solution of Eudragit S-100, using a pan coating equipment. PEG-600 $(1.25 \% \mathrm{w} / \mathrm{w})$ was used as a plasticizer. The percent weight increase of each batch of tablet after coating varied between $2.1 \pm 0.05 \% \mathrm{w} / \mathrm{w}$.

\section{Swelling studies}

Uncoated tablets with xanthan gum, pectin as binder in varying concentrations were subjected to swelling studies (Talukdar and Kinget et al., 1995 and Sujja-areevath et al., 1998) a temperature of $37^{\circ} \mathrm{C}$ and at a $\mathrm{pH}$ of 6.8 , using the same buffer that was used for dissolution studies. Swelling studies were
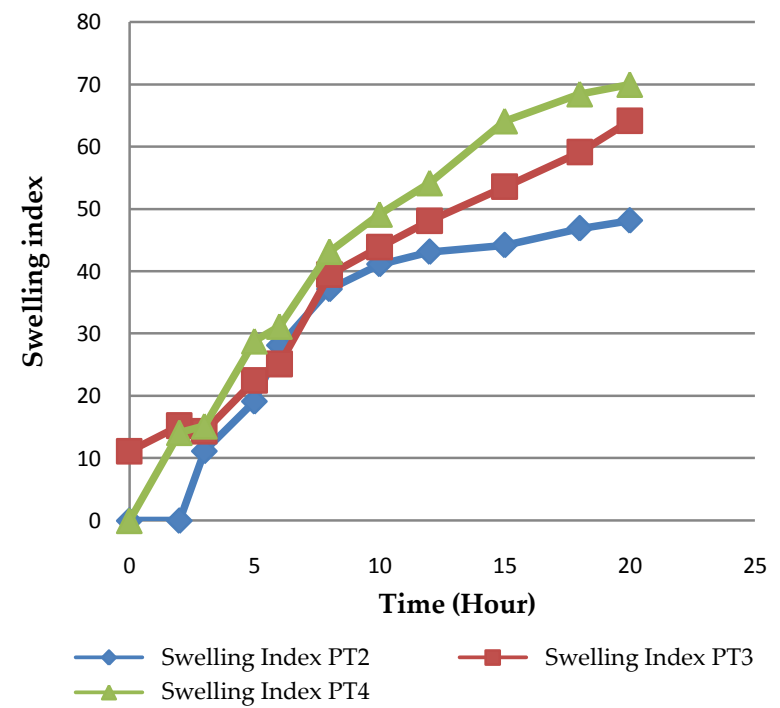

Figure 2: Swelling index vs. time graph of PT tablets at $6.8 \mathrm{pH}\left(37^{\circ} \mathrm{C}\right)$.

conducted in triplicate for each binder concentration. Radial swelling of tablet width was noted, manually from time to time (Fig. 1 and 2).

\section{Fourier Transform Infrared Spectroscopy}

The FTIR spectra were recorded using a JASCOFTIR-5300 spectrophotometer of meloxicam formulations were obtained by $\mathrm{KBr}$ pellet method. Infrared spectroscopy is one of the most powerful analytical techniques that offer the possibility of chemical identification. The various IR spectra of formulations prepared by xanthan gum, pectin, chitosan and Eudragit-E were obtained and studied for interaction patterns. The smoothing of the spectra and the baseline correlation procedures were applied. The FTIR measurements were performed in the scanning range of $4000-400 \mathrm{~cm}^{-1}$ at ambient temperature (Fig. 3).

\section{Drug release studies}

The ability of the prepared tablets to retard drug release in the physiological environment of the stomach and the small intestine was assessed by conducting drug release studies in simulated stomach and small intestinal $\mathrm{pH}$, respectively. Samples were withdrawn after regular intervals of time to evaluate drug release. These were analyzed spectrophotometrically at a wavelength of $269 \mathrm{~nm}$. 


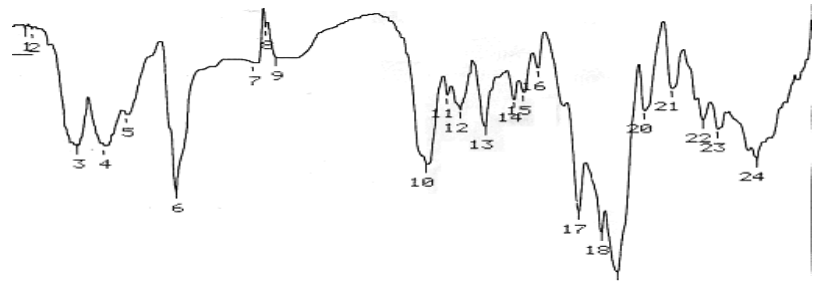

A) Meloxicam Pure Drug

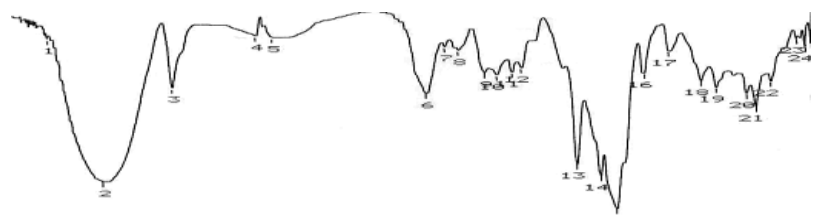

B) $\mathrm{CH} 4$ Formulation

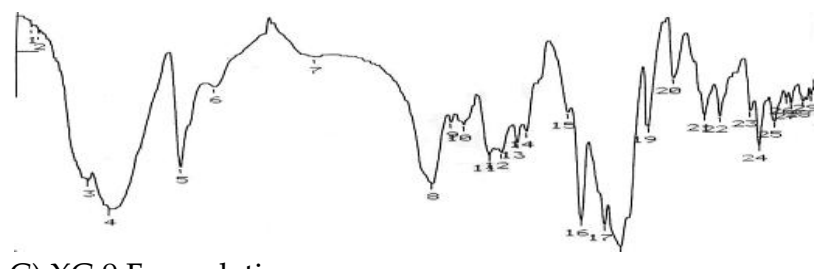

C) XG 9 Formulation

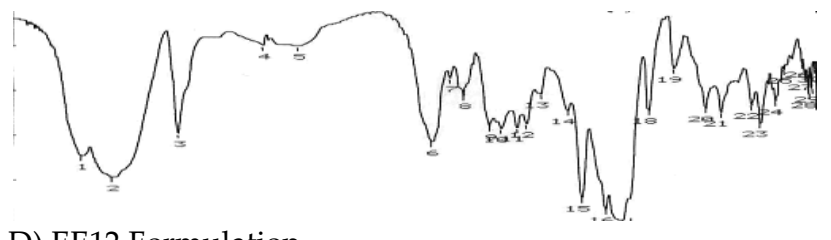

D) EE12 Formulation

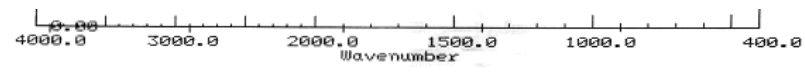

Figure 3: FT-IR Spectrum of Pure Drug and Prepared formulations.

\section{RESULTS AND DISCUSSION}

For the formulation of a delivery system for colon targeting, it is an essential prerequisite that the drug release should be minimal until the dosage form reaches the colon. The normal transit time in the stomach (gastric emptying time) is 2-3 h (though this may vary). The transit time in small intestine is relatively constant and is $3 \mathrm{~h}$. So, after gastric emptying, the drug release from the dosage form is to be retarded during transit through the small intestine $(3 \mathrm{~h})$. To overcome the variation in transit time of stomach the tablets prepared were enteric coated. None of the tablets showed drug release during the first 2-3 $\mathrm{h}$ in $0.1 \mathrm{~N} \mathrm{HCl}$, which is usual gastric emptying time. Enteric layer dissolved when

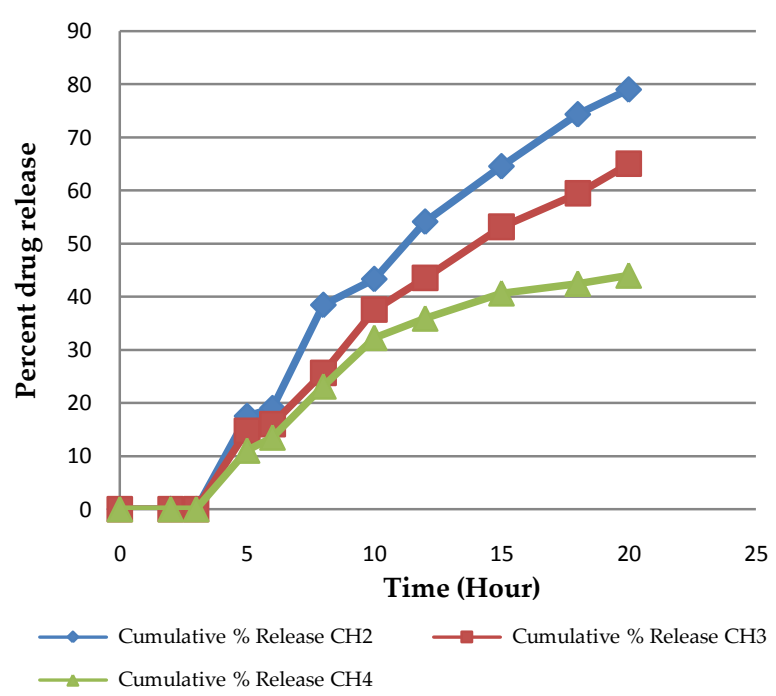

Figure 4: Percent drug release vs. time graph of $\mathrm{CH}$ tablets.

the $\mathrm{pH}$ was changed to 6.8 , and further drug release rate was dependent upon the type and concentration of binder used in the tablets.

\section{Chitosan as a binder}

$\mathrm{CH}$ tablets, using chitosan as a binder, studies showed that at a concentration of $1.77 \%$ (in $\mathrm{CH} 2$ tablets), the drug release in the initial $5 \mathrm{~h}$ was $19 \%$. Increasing the concentration of chitosan in the formulation from 1.18 to $1.77 \%$ in $\mathrm{CH} 3$, and then to $2.37 \%$ in $\mathrm{CH} 4$ tablets further retarded drug release from the dosage form. Percent drug release at $6 \mathrm{~h}$ was reduced to $16 \%$ in $\mathrm{CH} 3$ tablets and further to $13.5 \%$ in $\mathrm{CH} 4$ tablets. The total amount of drug released from $\mathrm{CH} 2, \mathrm{CH} 3$, and $\mathrm{CH} 4$ tablets was around $79 \%$, 65\% and 44\%, respectively in $20 \mathrm{~h}$ (Fig. 4, Table 2).

As the concentration of binder in the system is increased, hardness, porosity \& capillary sizes are reduced this decreases the wicking of water into the tablet, and reduces the disintegration as well as dissolution processes, this could be the reason behind decrease in release rate on increasing the concentration of chitosan. Drug release due to swelling \& polymer erosion was minimized as these formulated tablets did not show any signs of swelling in basic environment. This explains why the rate of drug release was not as high as in the case of other swellable gums. Once these $\mathrm{CH}$ tablets reach the colon, chitosan shall be broken down by 
Table 2: Cumulative percent drug release from the tablets at varying time intervals.

\begin{tabular}{lllll}
\hline $\begin{array}{l}\text { S1. } \\
\text { No. }\end{array}$ & $\begin{array}{l}\text { Formula- } \\
\text { tion code }\end{array}$ & $\begin{array}{l}\text { \% drug } \\
\text { release }(\mathbf{3 h})\end{array}$ & $\begin{array}{l}\text { \% drug } \\
\text { release }(\mathbf{6} \mathbf{~ h})\end{array}$ & $\begin{array}{l}\text { \% drug } \\
\text { release }(\mathbf{2 0} \mathbf{~ h})\end{array}$ \\
\hline 1 & XG3 & 0 & 29 & 71 \\
2 & XG6 & 0 & 26 & 83 \\
3 & XG9 & 0 & 32 & 100 \\
4 & PT2 & 0 & 48 & 100 \\
5 & PT3 & 0 & 57 & 100 \\
6 & PT4 & 0 & 51 & 100 \\
7 & CH2 & 0 & 19 & 79 \\
8 & CH3 & 0 & 16 & 65 \\
9 & CH4 & 0 & 13.5 & 44 \\
10 & EE3 & 0 & 74 & 100 \\
11 & EE6 & 0 & 39 & 91 \\
12 & EE9 & 0 & 27 & 75 \\
13 & EE12 & 0 & 18 & 48 \\
\hline
\end{tabular}

the microflora of the colon and the total amount of drug shall be released from the dosage form. These tablets can also tolerate variation in upper GIT transit time, since the rate of drug release before arrival into the colon remain retarded.

Thus, systems formulated using chitosan as a binder have been found to protect majority of drug release during the usual upper GIT transit time of $5 \mathrm{~h}$. There have been a number of reports where chitosan has been found to be digested by the microflora of the colon. However, Enteric-coated chitosan capsules have been known to be site specific for the colonic delivery of drug molecules, since they release the drug upon bacterial degradation in the colon (Tozaki et al., 1995; Tozaki et al., 1999) These tablets seem to be highly site specific because drug shall be released only upon specific bacterial degradation of the binding agent i.e. chitosan in the colon.

\section{Xanthan gum as binder}

$X G$ tablets due to the enteric coating did not show any drug release during the initial $3 \mathrm{~h}$ in the acidic media but once the $\mathrm{pH}$ was changed to 6.8 , drug release started, but at a retarded rate. Drug release from XG3 tablets in the next $3 \mathrm{~h}$ was $29 \%$ and a total of $71 \%$ of the drug was released in $20 \mathrm{~h}$. Increasing the concentration of XG from $1.77 \%$ (XG3) to $3.55 \%$ (XG6), decreased the initial amount of drug released, showing $26 \%$ release in the next $3 \mathrm{~h}$ but the total amount of drug release in $20 \mathrm{~h}$ was increased to $83 \%$. Further, increase in concentration of xanthan gum to $5.32 \%$ (XG9), though, initially reduced drug

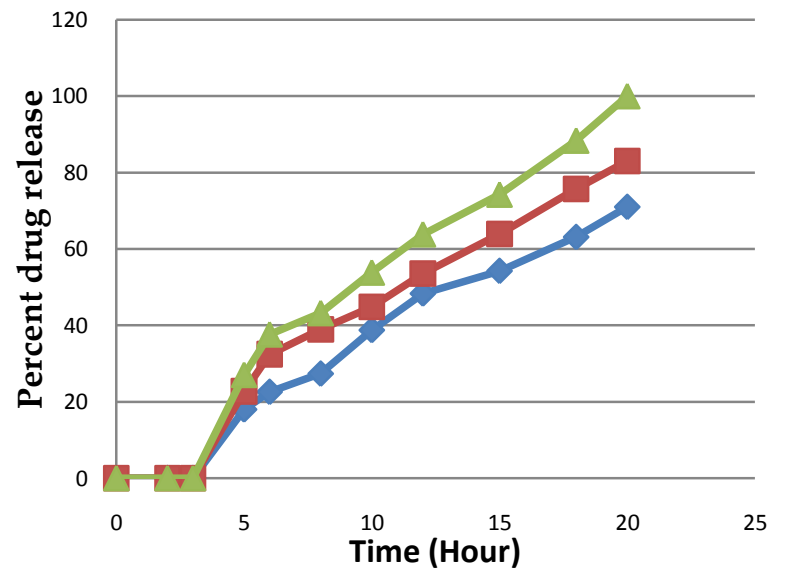

$\longrightarrow$ Cumulative \% Release XG3 $\longrightarrow$ Cumulative \% Release XG9
$\longrightarrow$ Cumulative \% Release XG6

Figure 5: Percent drug release vs. time graph of XG tablets.

release, but this was followed by a rapid drug release and nearly $100 \%$ drug was released in $20 \mathrm{~h}$. (Fig. 5). The initial decrease in drug release rate on increasing the concentration of xanthan gum can be explained on the basis that a higher binder concentration led to an increase in hardness of the tablet, while the porosity and capillary pore sizes were reduced (Upadrashta et al., 1992) This intern reduced the swelling, drug release rates are slowed and consequently wicking of water into the tablet.

During XG tablets study it was found that the drug was dispersed in the swollen matrix formed by the polysaccharide and tablets showed a considerable swelling at a $\mathrm{pH}$ of 6.8 (Fig. 1). The mechanism involved in the release of the active principle (drug) by a matrix system is generally produced by two simultaneous mechanisms: (a) dissolution of the active principle in the liquid medium and diffusion through the gel barrier when formed, (b) erosion or attrition of the outermost, least consistent gel layer (Lapidus and Lordi, 1968, Feely and Davis, 1988; Alderman, 1984) Moreover, studies carried out on swellable matrices have shown that as the concentration of the swellable polymer is increased in the formulation, the gel thickness increases upon swelling. This increases the diffusion path length, which in turn decreases the drug release from the tablet (Talukdar and Kinget, 1995) However, in present study it was noticed that upon increasing the concentration of polysaccharide swelling also 


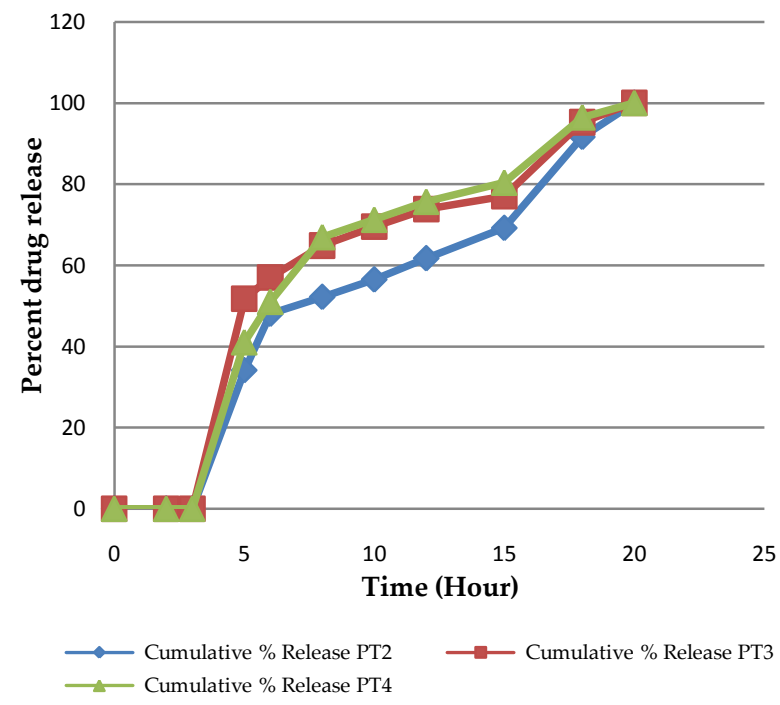

Figure 6: Percent drug release vs. time graph of PT tablets.

increased. But after certain time period drug release was increased further rather than decreased. The reason behind this could be attributed to the basis that these tablets upon swelling form rather loose gels due to a very low concentration of the polysaccharide. Since the release of drug from these matrices takes place by polysaccharide erosion, which further depends upon the gel consistency (Marcos et al., 1991) looser the gels, the more susceptible the matrix is to erosion and faster is the drug release.

This study shows that XG can be used to formulate time-controlled release systems for colon targeting as a binder which initially retards drug release due to the lag time required for swelling and after swelling, a rapid drug release was obtained.

\section{Pectin as a binder}

Pectin (PT) tablets show a rather rapid drug release after second hour of dissolution showing that as the enteric layer dissolved, the pectin used as a binder could not effectively retard drug release. The cumulative percent drug release versus time profile proved the same. In PT2 tablets with a concentration of $1.18 \%$ of pectin, drug release could not be retarded. Increasing the concentration of pectin in the tablet from 1.18 to $1.77 \%$ and then to $2.37 \%$ did retard the drug release profile further but a significant reduction was not observed. The percent drug release versus time graph shows that as much as 48 ,

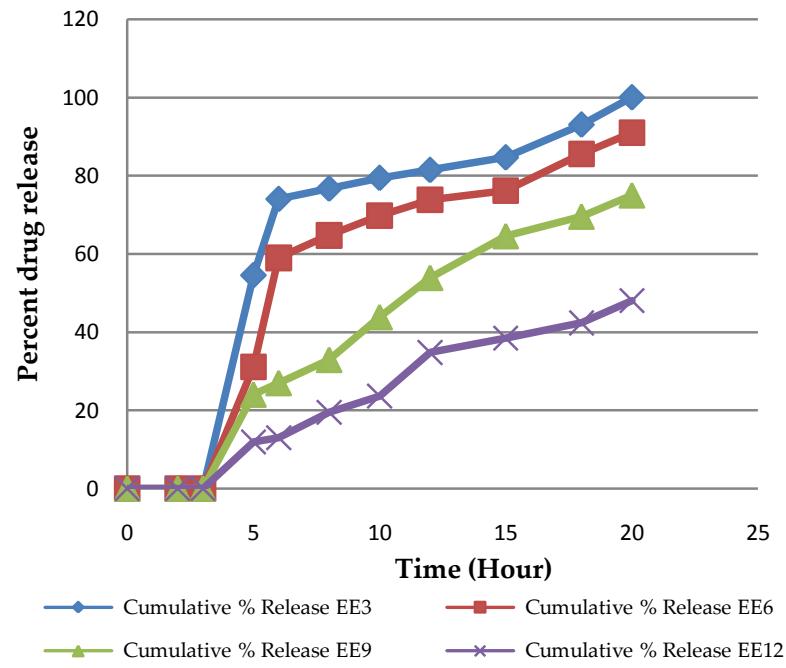

Figure 7: Percent drug release vs. time graph of EE tablets.

57 and $51 \%$ drug release was observed in the first 6 $\mathrm{h}$ of dissolution of PT2, PT3 and PT4tablets, respectively (Fig. 6). Complete drug was release from the tablets at around 20th h.

Increase in swelling index (Fig. 2) was observed with increase in concentration of pectin in PT tablets but the drug release was not much affected and no optimum lag time was achieved as required to bypass the drug release in upper parts of GIT. The reason could be attributed to lower swelling of pectin tablets and also probably, the concentration of the pectin present was not sufficient to retard the drug release.

\section{Eudragit $\mathrm{E}$ as binder}

The cumulative percent drug release versus time profile proved that $\mathrm{EE}$ tablets protected drug release for an initial $3 \mathrm{~h}$ in acidic media. In the basic environment $(\mathrm{pH}$ 6.8) the enteric layer dissolves, and Eudragit-E, being soluble only at lower $\mathrm{pH}$ values (lower than 5) finds an unfavorable environment for dissolution and thereby drug release was retarded (Fig. 7). However, a concentration of $1.77 \%$ (i.e. in EE3 tablets) was not able to protect drug release from the tablets and a sharp increase in drug release was observed with-in the next $1 \mathrm{~h}$ and $74 \%$ of drug release was observed in the $6 \mathrm{~h}$. After increasing the concentration of the binder Eudragit $\mathrm{E}$ in the tablet to $3.55 \%$ (EE6 tablets) the drug release during the first $6 \mathrm{~h}$ of dissolution was retarded 
showing percent drug release of around $39 \%$ as against $74 \%$ in EE3 tablets. Further increase in concentration of binder to 5.32 and then to $7.10 \%$ in EE 9 and EE 12 tablets, reduced percent drug release in first $6 \mathrm{~h}$ to $27 \%$ and $18 \%$, respectively. The total amount of drug released in $20 \mathrm{~h}$ reduced from 100 to $91 \%$ followed by 75 and then $48 \%$ in EE3, EE6, EE9 and EE12 tablets, respectively (Table 2). Reason behind reduction in rate of drug release upon increasing the concentration of binder can be explained on the assumption that upon drying of granules a film is formed by the binder over the granules (Yen et al., 1964 and Bankar et al., 1992). Due to increase in the concentration of binder, thicker film of Eudragit E was formed around the granules, which retarded the drug release because of being insoluble at a $\mathrm{pH}$ of 6.8 . The thickness of the film depends upon the concentration of binder used.

\section{CONCLUSION}

Systems formulated using chitosan as binders seem to be highly site specific due to release of majority of drug only upon breakdown by the bacterial microflora of the colon. These formulations could act as colon specific drug delivery systems using as low as $2 \%$ of chitosan as binders. Such a low concentration of chitosan has shown high site specificity. An additional advantage of these systems is that they could be formulated easily, using the usual tableting and coating techniques. These systems seem to be promising for delivery of water insoluble drugs to the colon. The use of $5.32 \%$ of xanthan gum as binder could formulate time-controlled release formulations, which could carry a high percentage of drug to the terminal ileum or the colon. Systems formulated using upto $2 \%$ of guar gum could not carry the drug to the colon. Moreover, Systems formulated with $7.10 \%$ of Eudragit $\mathrm{E}$ as binders could be used to deliver water insoluble drugs sitespecifically to the colon in IBD.

\section{ACKNOWLEDGEMENT}

The authors were grateful to the Principal, Padmashri Dr. Vitthalrao Vikhe Patil Foundation's College of Pharmacy, Vilad Ghat, Ahmednagar-414111, Maharashtra, India for providing necessary facilities for carrying out the current studies.

\section{REFERENCES}

Alderman, D.A. (1984). A review of cellulose ethers in hydrophilic matrices for oral controlled-release dosage form. Int. J. Pharm. Tech. Prod. Mfr. 5, 1-9.

Banakar, U.V. (1992). Factors that influence dissolution testing. In: Pharmaceutical Dissolution Testing. Marcel Dekker, New York, p. 149.

Chandel, A., Chauhan, K., Parashar, B., Kumar, H., Arora, S. (2012). Floating drug delivery systems: A better approach, International Current Pharmaceutical Journal 1(5): 110-118. [DOI]

Chourasia, M.K., Jain, S.K. (2003). Pharmaceutical approaches to colon targeted drug delivery systems, J Pharm Pharmaceut Sci 6(1): 33-66.

Feely, L.C., Davis, S.S. (1988). Influence of polymeric excipients on drug release from hydroxypropyl methyl cellulose matrices. International Journal of Pharmaceutics, 44(1-3): 131-139. [DOI]

Kinget, R., Kalala, W., Vervoort, L., Mooter, G.V. (1998). Colonic drug targeting. J. Drug Target 6, 129-149. [DOI]

Leopold, C. (1999). Coated dosage forms for colon-specific drug delivery, PSTT 2 (5) 197-204.

Liu, L.S. M.L. Fishman, J. Kost, K.B. Hicks, (2003). Pectinbased systems for colon-specific drug delivery via oral route, Biomaterials 24 3333-3343. [DOI]

Lapidus, H., Lordi, N.G., (1968). Drug release from compressed hydrophilic matrices. J. Pharm. Sci. 57, 1292-1301. [DOI]

Marcos, B.P., Gutierrez, C., Gomez-Amoza, J.L., Martinez. Pacheco, R., Souto, C., Concheiro, A. (1991). Usefulness of certain varieties of carbomer in the formulation of hydrophilic furosemide matrices, International Journal of Pharmaceutics, 67(2): 113-121. [DOI]

MacNeil, M.E., Stevens, H.N.E., (1990). Patent WO 90/09168. [DOI]

Niwa, K., Takaya, T., Morimoto, T., Takada, K., (1995). Preparation and evaluation of a time-controlled release capsule made of ethylcellulose for colon delivery of drugs. J. Drug Target. 3, 83-89. [DOI]

Ojha, M., Madhav, N.V.S., Singh, A. (2012).Synthesis and evaluation of sodium carboxymethyl cellulose azo polymer for colon specificity. International Current Pharmaceutical Journal, 1(8): 209-212.

Reddy, S.M., Sinha, V.R., Reddy, D.S. (1999). Novel oral colon specific drug delivery systems for pharmacotherapy of peptide and non-peptide drugs, Drugs Today, 35:537-580.

Sinha,V.R., Kumria,R. (2001). Polysaccharides in colonspecific drug delivery, Int. J. Pharm. 224 19-38. [DOI]

Sinha,V.R., Kumria, R. (2003). Microbially triggered drug delivery to the colon, Eur. J. Pharm. Sci. 18,3-18. [DOI] 
Sujja-areevath, J., Munday, D.L., Cox, P.J., Khan, K.A., (1998). Relationship between swelling, erosion and drug release in hydrophilic natural gum mini-matrix formulations. Eur. J. Pharm. Sci. 6, 207-217. [DOI]

Talukdar, M.M., Kinget, R., (1995). Swelling and drug release behavior of xanthan gum matrix tablets. Drug Dev. Ind.Pharm. 120, 63-72. [DOI]

Tozaki, H., Komoike, J., Tada, C., Maruyama, T., Terabe, A.,Suzuki, T., Yamamoto, A., Muranishi, S., (1997). Chitosan capsules for colon specific drug delivery: improvement of insulin absorption from the rat colon. J. Pharm. Sci. 86, 1016-1021. [DOI]

Tozaki, H., Fujita, T., Odoriba, T., Terabe, A., Suzuki, T., Tanaka, C., Okabe, S., Muranishi, S.S., Yamamoto, A., (1999). Colon specific delivery of R68070, a new thrombox ane synthase inhibitor, using chitosan capsules: therapeutic effect against 2,4, 6,-trinitrobenzene sulphonic acidinduced ulcerative colitis in rats. Life Sci. 64, 1155-1162.

Upadrashta, S.M., Katikaneni, P.R., Nuessle, N.O., (1992). Chitosan as a tablet binder. Drug Dev. Ind. Pharm. 18, 1701-1708. [DOI]

Yang, L., Chu, J.S., Fix, J.A. (2002). Colon-specific drug delivery: new approaches and in vitro/in vivo evaluation, Int. J. Pharm. $235,1-15$. [DOI]

Yen, J.K. (1964). The dissolution rate principle in practical tablet formulation. Can. Pharm. J. 97, 493-499. 